\title{
DYNAMICS, SYNERGETICS, AUTONOMOUS AGENTS
}




\title{
STUDIES OF NONLINEAR PHENOMENA IN LIFE SCIENCES
}

Editor-in-Charge: Bruce J. West

\author{
Vol. 1: Fractal Physiology and Chaos in Medicine \\ by $B J$ West
}

Vol. 2: Patterns, Information and Chaos in Neuronal Systems edited by $B J$ West

Vol. 3: The Lure of Modern Science - Fractal Thinking by $B J$ West \& B Deering

Vol. 4: Physical Theory in Biology - Foundations and Explorations edited by C J Lumsden, W A Brandts \& LE H Trainor

Vol. 5: Nonlinear Dynamics in Human Behaviour edited by $W$ Sulis \& A Combs

Vol. 6: The Complex Matters of the Mind edited by F Orsucci

Vol. 7: Physiology, Promiscuity, and Prophecy at the Millennium: A Tale of Tails by $B J$ West 
Studies of Nonlinear Phenomena in Life Science - Vol. 8

\section{DYNAMICS, SYNERGETICS, AUTONOMOUS AGENTS}

Nonlinear Systems Approaches to Cognitive Psychology and Cognitive Science

\section{Editors}

\section{W. Tschacher \\ University of Bern \\ J.-P. Dauwalder}

University of Lausanne 
Published by

World Scientific Publishing Co. Pte. Ltd.

P O Box 128, Farrer Road, Singapore 912805

USA office: Suite 1B, 1060 Main Street, River Edge, NJ 07661

UK office: 57 Shelton Street, Covent Garden, London WC2H 9HE

\section{British Library Cataloguing-in-Publication Data}

A catalogue record for this book is available from the British Library.

\section{DYNAMICS, SYNERGETICS AND AUTONOMOUS AGENTS: \\ Nonlinear Systems Approaches to Cognitive Psychology and Cognitive Science \\ Copyright (C) 1999 by World Scientific Publishing Co. Pte. Ltd. \\ All rights reserved. This book, or parts thereof, may not be reproduced in any form or by any means, electronic or mechanical, including photocopying, recording or any information storage and retrieval system now known or to be invented, without written permission from the Publisher.}

For photocopying of material in this volume, please pay a copying fee through the Copyright Clearance Center, Inc., 222 Rosewood Drive, Danvers, MA 01923, USA. In this case permission to photocopy is not required from the publisher.

ISBN 981-02-3837-1 


\section{CONTENTS}

Foreword

Hermann Haken

Introduction

Wolfgang Tschacher

Why Dynamics? Because it Tackles Real Issues.

Francisco Varela

\section{Theory and Concepts}

Synergetics and Some Applications to Psychology

Hermann Haken.

Defending the Dynamical Hypothesis

Tim van Gelder

From Continuous Dynamics to Symbols

Herbert Jaeger

On Measures for Order and its Relation to Complexity

John Shiner, Matt Davison, and Peter Landsberg ....

Synergetics of Human Creativity

Helena Knyazeva and Hermann Haken.

\section{Dynamical Concepts in Cognitive Psychology}

Situated Cognition, Ecological Perception, and Synergetics: A Novel Perspective for Cognitive Psychology?

Wolfgang Tschacher and Jean-Pierre Dauwalder.

Attitudes and the Self as Self-Organising Systems

Richard Eiser

An Affect-Centered Model of the Psyche and its Consequences for a New

Understanding of Nonlinear Psychodynamics

Luc Ciompi....

Formation and Adaptation of Schemata

Thomas Bröcker and Jürgen Kriz 
Simulations of Stagewise Development with a Symbolic Architecture Fermand Gobet

\section{Autonomous Agents}

The Embodied Cognitive Science Approach

Christian Scheier and Rolf Pfeifer

A Computational Model of Spatial Development

Kazuo Hiraki, Akio Sashima, and Steven Phillips....

Societies of Autonomous Agents and their Reorganization

Norbert Glaser and Philippe Morignot

Investigations into Internal and External Aspects of Dynamic

Agent-Environment Couplings

Kerstin Dautenhahn....

A Formal Theory for Collective Intelligence

William Sulis

\section{Empirical studies}

The Detection of Catastrophe Flags in Personally Relevant Decisions Marc Coulson and Stephen Nunn

Synergetic Organization in Speech Rhythm

Fred Cummins

Exploring the Dynamics of Personality Change with Time Series Models

Ferdinand Keller, Maja Storch and Susanne Bigler

Hierarchical Dynamics Affecting Work Performance in Organizations

Stephen J. Guastello

List of Contributors 303

Author Index 305

Subject Index 


\section{FOREWORD}

The understanding of cognition is certainly one of the most challenging endeavours of the human mind. The present book, edited by Wolfgang Tschacher and Jean-Pierre Dauwalder, reflects modern trends to which these editors as well as others have given significant impulses. We are increasingly adopting ideas that the human mind and its material substrate, the brain, obey principles that govern a quite fundamental phenomenon of nature, namely that of self-organization.

The problem of cognition thus appears in a new light. A number of these ideas can now be formulated by using concepts from the interdisciplinary field of synergetics. It is certainly not a coincidence that almost simultaneously a similar trend becomes apparent in the United States, where quite often the theory of synergetics and its implications have been applied in the study of psychological phenomena including that of cognition.

There is a closely related development that is also well documented by this volume, namely that the material basis of the mind, or rather its implications, can be studied by model systems using robots. These developments can be characterized as the study of embodied cognition and its realizations by individual autonomous agents or systems of autonomous agents.

All in all, it can be said that we are presently witnessing the development of a new attempt of the human mind to understand itself by means of a unifying concept -that of self-organization - which comprises both the animate and inanimate world.

I wish to congratulate the editors of this volume for their highly successful selection of contributions and topics that underline this novel way of thinking. 
This page is intentionally left blank 


\section{INTRODUCTION}

Cognition is at the heart of both psychology and computer science. Not too long ago, psychologists would have had considerable doubts about this statement-are not behavior and action closer to the scientific core of their discipline? Computer science has not been prone to such ambivalence, provided that cognitive processes were understood as the processing of symbolic tokens ready to be implemented on any material substrate. This situation underwent an ironic change in recent decades. Psychology was deeply impressed by the artificial intelligence engineers' success in performing information processing on machines, and the mainstream of psychology even adopted a computational foundation for cognitive psychology. But almost at the same time, computer scientists grew increasingly disenchanted with their approach towards intelligence. Thus, while psychology turned more and more computationalist, computer science had, in a way, become more psychological, and had started to consider concepts such as embodiment, semantic grounding of symbols and the different facets of the mind-body problem.

Our intention with this volume is to help synchronize and integrate the progress made in both cognitive psychology and new artificial intelligence. A guiding idea is that complexity theory and dynamics may considerably facilitate this endeavour. The dynamical approach introduces the language and method of dynamical systems theory - with key concepts such as attractor, bifurcation, etc-to cognition research. Complexity theory, in the shapes of self-organization theory and synergetics, adds to this method by considering evolution, i.e. the emergence of patterns in open, nonlinear systems. Order may evolve from the cooperation, the 'synergy' of microscopic components of a system.

The concept of autonomous agents put forward by designers of robots has many parallels with this dynamical approach. Autonomous agents can never be completely pre-programmed so that much thought must be invested on their embeddedness in an environment. The question arises of how stable and adaptive behavior can grow out of this interaction between agent and environment. This may be rephrased in a synergetic manner to address the interaction between a complex open system and environmental control parameters, which results in pattern formation. In this way, the models of synergetics can be applied to autonomous agents. In turn, the problem of autonomous agents is obviously analogous to the problem of action control and volition. This is why psychology is directly addressed, too.

This volume-in negotiating the topic of cognition between the perspectives of cognitive psychology, AI, and dynamics-is divided into four sections. The first of these, 'Theory and Concepts', is initiated by Hermann Haken's treatment of how perception, cognition and decision-making may be modeled by synergetics. Tim van 
Gelder disputes the various objections that may be made to the "dynamical hypothesis' in cognitive science. Herbert Jaeger proposes the concept of 'dynamical symbols', i.e. dynamical events that have the qualities of symbols. The contribution of John Shiner, Matt Davison, and Peter Landsberg centers on methodology; they investigate an algorithm to assess order (e.g. in psychological data) which circumvents the problems of complexity measures. Helena Knyazeva and Hermann Haken explore the heuristic value of synergetics by applying it to human creativity and innovative thinking.

The second section, 'Dynamical Concepts in Cognitive Psychology', gives an account of cognitive dynamics as viewed from the perspective of psychology. Wolfgang Tschacher and Jean-Pierre Dauwalder introduce this section by pointing out the shortcomings of the standard approaches of information processing and action theory, and by suggesting a dynamical, situated model. The contribution of Richard Eiser puts forward an alternative to core concepts in social psychology, such as attitude and self, by advocating a self-organized systems view. Luc Ciompi argues for an emphasis on the significance of affects in mental functioning, thereby laying the foundation for the approach of 'fractal affect-logic' Thomas Bröcker and Jürgen Kriz elaborate Bartlett's and Piaget's schema theories in terms of synergetics. Taking a developmental perspective, Fernand Gobet is also concerned with the Piagetian concepts of assimilation and accommodation, which he then models in a symbolic framework.

The third section concerns 'Autonomous Agents' Christian Scheier and Rolf Pfeifer outline their research program of 'embodied cognitive science' by elaborating principles for the design of artificial autonomous agents. Kazuo Hiraki, Akio Sashima, and Steven Phillips investigate how self-locomotion interacts with the development of spatial cognition in a robot experiment. Norbert Glaser and Philippe Morignot lay the conceptual foundation for the study of societies of autonomous agents. Kerstin Dautenhahn emphasizes the importance of a concept of the body - a body image-in social agents. William Sulis presents a conceptualization of 'collective intelligence', i.e. adaptive behavior found in swarms or societies of simple autonomous agents.

The concluding fourth section adds (further) 'Empirical Studies' Marc Coulson and Stephen Nunn test hypotheses of the nonlinearity of cognition (so-called 'catastrophe flags') in experiments on decision-making. Fred Cummins applies the Haken-Kelso-Bunz model of rhythmic coordination to human speech. Ferdinand Keller, Maja Storch and Susanne Bigler operationalize personality changes induced by Jungian psychological intervention using a time series approach. Stephen Guastello studies work behavior in hierarchical organizations in the framework of game theory and chaos theory.

A major incentive for this volume came from a conference we organized in Gstaad, Switzerland, in March 1997. Several of the contributions are based on lectures given 
in Gstaad, others have been written in the wake of the conference especially for the scope of this book.

The Gstaad conference was seventh in the series of Herbstakademie symposia that are targeted at elucidating the relationship between self-organization theory and psychology. Aside from providing a platform for the ongoing Herbstakademie discussions, which traditionally are attended by German-speaking researchers, the Gstaad symposium was also the 'First Joint Conference on Complex Systems in Psychology'. Therefore, the editors of this volume wish to thank the Society for Chaos Theory in Psychology and the Life Sciences, and especially its past presidents Stephen Guastello, Bill Sulis and Fred Abraham, for their stimulating joint cooperation. We are also indebted to Günter Schiepek and Ewald Johannes Brunner who have both been instrumental in organizing Herbstakademie meetings since 1990. Hermann Haken has been a peerless mentor throughout these years.

We would like to extend our thanks to all those who contributed to the success of the Gstaad meeting, notably Nicole Baur, Philippe Lemay and Barbara ZumsteinMiller. The financial support given by the Université de Lausanne, the Universität Bern, and the Swiss graduate program 'troixiéme cycle romand' is gratefully acknowledged.

Concerning the production of this book, we appreciate the excellent job Nicole Baur did during the complete editing process. We also thank Barbara ZumsteinMiller for her assistence in language-editing some of the manuscripts. Last but not least, Kim Tan of World Scientific and the series editor Bruce West were pleasant and efficient partners in the realization of this project.

Bern, December 1998

Wolfgang Tschacher

Jean-Pierre Dauwalder 
This page is intentionally left blank 


\section{WHY DYNAMICS? BECAUSE IT TACKLES REAL ISSUES.}

For many years, in fact since the inception of cognitive science, the framework of a representational theory of mind has provided conceptual support to research on the question of cognition, tractable under the information-processing approach. The level of description opened by the concept of information processing is still the decisive notion for most of cognitive science because the relevant disciplines of the hard sciences-for instance AI, neural networks, and cognitive psychology-mostly operate on this conceptual level. Put in a more concrete fashion, one tries to analyze mind and cognition as a complex information-processing event in the brain. This would then also have to be applied to singular elements of the experiential space, such as for instance, to the phenomenal self or to qualia.

Recently, however, a flood of completely new concepts, many of which are often very hard to understand, have been introduced by numerous researchers who take an interdisciplinary opening of a science of mind seriously. These are concepts such as activation vectors, non-linear effects and measures, trajectories through neural spaces, attractors, neural binding and temporal coding. This colorful and contingent list could easily be continued. They all can be arranged under one big, encompassing umbrella: that of dynamics as the central frame, highlighted by the contributions of Part I of this volume. Not representational models with symbolic contents, but active agents with dynamical architectures are considered. This shift in perspective is, no doubt, the most important transformation that cognitive science has witnessed. It is here to stay, as attested to by the contents of Part I of this volume, along with a growing literature on the subject.

Why should this dynamical turn be so significant? I would say because it tackles two really hard issues: the alternative to representations, and the causal level of a cognitive subject. Let me address these two issues separately.

First, dynamical approaches are essential because they free us from the straightjacket of a representational mind by postulating, instead, mind as an emergent phenomena which is anchored in its immediate coping with its world. For a cognitive agent conceived as a dynamical network, coupling with the world will create regularities, which are, de facto, the objects that populate its world. This is the central idea of an embodied, situated or enactive cognitive science. This epistemic shift, made largely possible by the technical tools of dynamical systems. cannot be underestimated, and we are far from having extracted all its consequences. One of the most dramatic examples of this impact are the new schools of artificial intelligence based on autonomous agents, as seen in the papers in Part III of this volume. The very use of the word 'autonomous' already is a give-away that these are not representational, but actively presentational machines. 
The second central aspect introduced by dynamics is the new status given to the cognitive agent. In fact, if the proper level of analysis of cognition is as an emerging property from dynamical principles, a separate question is its causal efficacy. Can a mental subject actually bear effectively on the elements and properties that are needed to give rise to it? This issue is particularly important in psychology for it defines the status of the 'self', the level required by psychologically motivated questions. As several contributions in Part II of this volume show, an emergent cognitive agent is intrinsically endowed with the capacity to affect the levels of constitutive elements. This is simply due to the fact that the cognitive subject as a global emergent level acts directly as a constraint on the local level. We are landed with a double causality across levels, effective passages between the local and the global. Epistemically this solves the old quandary concerning the apparently epiphenomenal status of the subject, and illuminates a host of phenomena in psychology from emotions to somatisation.

Although much more must be achieved before we arrive at a mature dynamical cognitive science and psychology, this volume adds significant steps. It is now time to turn to these voices.

Paris, November 1998

Francisco J. Varela 